ists, it is impossible to deny the favorable influence which the injections exert on these localized lesions. This may be due, however, to the many imperceptible focal reactions brought about by the injections and not to any general specific immunity.

If we must have a working theory and must decide between the two, I prefer for the present to hold to the conception of an immunity that is principally at least antitoxic as produced by the treatment, and to consider tuberculin habituation its essential feature and the best guide to dosage. This conception does not lead us to expect too much; it is more in keeping with what we observe clinically as a result of treatment, and explains its very evident limitations. It is also in accord with experimental evidence which shows that vaccinations with living cultures alone produce any real immunity to subsequent tuberculous infection, and that no specific antibacterial immunity worthy of the name can be brought about in animals by dead germs or chemical products derived from cultures.

\section{MAIN FEATURES OF TREATMENT}

If we accept the toxin immunization conception as the essential feature and guide to the treatment, instead of measuring the degree of a questionable antibacterial immunity by the opsonic index, or attempting to produce it more or less empirically by a series of moderate reactions, the severity of which we can not in any way control, the main features in our treatment would be:

1. To raise the degree of tolerance to tuberculin to the highest point attainable in each case by an almost imperceptible and long-continued progression in dosage.

2. To avoid general and focal reactions as much as possible and consider them merely as evidences of in. tolerance.

3. To follow no arbitrary rule as to rate of increase or the maximum dose to be reached, but to be guided merely by the degree of toxin tolerance of each patient as shown by the symptoms and general condition, whether the highest individual maximum dose attainable be only a small fraction of a milligram or a cubic centimeter or more.

\section{HYPEREMIC TREATMENT IN GYNECOLOGY ANI) OBSTETRICS * \\ ARTHUR STEIN, M.D. \\ NEW YORK}

The marked operative tendency which existed among gynecologists toward the end of the last century was naturally followed by a more conservative era. Signs were not wanting that the pendulum had reached the limit of its swing toward the operative side and that its return movement had begun. At one of the New York medical societies Emmet ridiculed the common occurrence of presenting large jars with uterine adnexa at gynecologic meetings. Ramy, ${ }^{1}$ in a warning against operating without indication, ironically called atte tion to the fact that at some gynecologic meetings the surgeons who reported the most radical operations on the female genital organs received the greatest recognition. After these and similar warnings the question naturally arose whether it was not possible to attain normal conditions or nearly

* Read at a meeting of the Harlem Medical Society, New York, Oct. 7,1908 .

1. From Pincus: Belastungslagerung, p. 5, Wiesbaden, 1905 such in the fermale pelvis with non-operative methods. It is not to be denied that the non-operative treatment often requires weeks to accomplish its end and that it, therefore, taxes the patience both of the physician and patient. The result will in most instances amply justify the trouble and time bestowed on the treatment, as normal organs, of normal function, will often be preserved.

The trend toward conservative gynecology came at a time when in general surgery efforts were being made to avoid operations as much as possible in acute and chronic inflammatory conditions. In this work Bier was the pioneer. Though not the first to introduce special apparatus for the production of artificial hyperemia (Ambrose Paré seems to have been the first, and Jules Guyot ${ }^{2}$ in 1835 described a hot-air apparatus), he placed hyperemic treatment, which had been used empirically for centuries, on a scientific basis and gave new impulse to this form of treatment. Bier demonstrated its great practical value and usefulness. After the surgeons grasped the indications for, and technic of, producing artificial hyperemia, and had gained some experience with the method in minor surgical conditions, the gynecologist was not slow to adopt it in the treatment of the diseases of women.

It would lead too far to consider here the many theories advanced in the explanation of the effects of artificial hyperemia and to go into details regarding hyperemia in general; these can be found in Bier's ${ }^{3}$ book and in Willy Mever and Schmieden's ${ }^{4}$ recent publication. Suffice it to say that there are two kinds of artificial hyperemia: active or arterial hyperemia produced by means of hot air, and passive or venous, brought about by cupping glasses or the elastic bandage. What artificial hyperemia particularly attains is diminution of pain. While it is not possible to suppress every infection before pus is formed, there is no doubt that, by means of artificial hyperemia, suppuration can be avoided in a large percentage of cases. In cases in which pus has formed it must, of course, be evacuated, but the hyperemic treatment enables us to accomplish with small incisions what formerly could be accomplished only with large disfiguring ones. By increasing the supply of blood the course of the pathologic process is hastened and absorption is favored.

\section{INDICATIONS FOR DRY HOT-AIR HYPEREMIA}

Turning to the discussion of the treatment of gynecologic and obstetrical conditions with artificial hyperemia, I shall consider first active hyperemia produced by dry hot air. This has been extensively used by the gynecologist, but has not received the attention of the general practitioner which it deserves. The latter frequently has the opportunity to treat gynecologic conditions in which the hot-air treatment is applicable, and the could use this just as well as the specialist can, for I believe that nothing is easier in private practice than to apply this form of treatment in diseases of the female generative organs.

As regards its indications and contraindications, it must be emphasized that fever, when it is caused by the pelvic trouble, is a positive contraindication, as are pregnancy and hemorrhage when not of ovarial origin; thus it is contraindicated during menstruation and in hemor-

2. Guyot, Jules: Arch. gén. de méd., series 2, 1835, viii.

3. Bier, August : Die Hyperämie als Heilmittel, Leipzig, 1906.

4. Bier's Hyperemic Treatment, Philadelphia, 1908, W. R Saunders \& Co. 
rhagic endometritis. Advanced pulmonary and cardiac disorders are also contraindications. The large field in which it is applicable includes chronic inflamed adnexa, pelvic exudates, chronic parametritis, and perimetritis, contracted painful scars, and fixed malposition of the uterus and its adnexa when the result of inflammatory processes.

It frequently happens that patients who have had no fever get a sudden rise of temperature immediately after the first hot-air treatment. This occurrence indicates the presence of an old encapsulation of pus somewhere in the inflammatory process, one that had not been detected by the finger of the examiner. In such cases it is best to stop the treatment and to try to bring about an absorption of the pus by other means. When the latter has taken place the hot-air therapy can be continued. Of course, I would not advise against it if there is only a slight elevation of temperature. Whether or not the treatment is to be adopted must be left to the judgment of the attending physician in each individual case. The fact that the presence of a small collection of pus causes the body to react so readily to hot air has led to the use of the latter as a diagnostic measure. I have seen many cases in which hot-air treatment was given in order to reach a definite conclusion as to whether pus was present or not. We must remember that the old saying, "vbi pus ibi evacua," has not become obsolete since the introduction of Bier's hyperemia. Pus when present must always be evacuated by surgical means.

\section{APPARATUS FOR HOT-AIR TREATMENT}

The hot-air treatment may be applied in two different ways, by means of hot-air chambers and by the hot-air vaginal douche. I shall confine myself, however, to the former, as the hot-air chambers are just as convenient to use and far more effectual than the douche. According to the simplicity of construction, the hot-air boxes or chambers may, for convenience, be divided into three groups. The first group includes the now obsolete Roth apparatus, which consists of two parts, an asbestos cylinder and a separate hot-air chamber which surrounds the asbestos; its application is cumbersome and complicated and is, therefore, not to be recommended. The second and third groups include apparatus of simple construction, box-like chambers, quadrangular or cylindrical in shape, which encompass the pelvis of the patient.

For all practical purposes the easiest way to give hotair treatment in private is to use the ordinary semicircular cradle. This is placed over the patient's pelvis and made air-tight by putting blankets over it. The hot air is carried into the chamber through a small funnelshaped sheet-iron chimney (the well-known Quincke chimney) ; an alcohol-lamp or a Bunsen burner placed on a stand underneath the funnel supplies the heat. E. Kehrer recommends the use of electric light bulbs on the inner side of the cradle to supply the necessary heat. He has obtained good results in this way, and it must be admitted that this method has the advantage of being clean. (Colored bulbs should be used, as they prevent the chemically effectual rays from reaching the patient.) Every apparatus should be supplied with a well-constructed thermometer to avoid burns.

\section{RESULTS OF HOT-AIR TREATMENT}

The chief physiologic function of dry hot air is the production of an active hyperemia, an increased supply of arterial blood. Bier attributes the curative qualities of this mode of treatment to the fact that it causes more blood to flow through the diseased tissues in a given time, rather than to the increased supply of oxygen brought to the part. Klapp's experiments have demonstrated that not only the skin but the abdominal contents as well become hyperemic. In this way the tissues are better nourished, their regenerative functions are stimulated to greater activity, and an increased local metabolism is established. Perspiration is increased and through its evaporation the skin is cooled; this explains the fact that temperatures from 210 to $230 \mathrm{~F}$. can be tolerated. It must be borne in mind that advanced pulmonary or cardiac disease are contraindications for this treatment and that therefore the lungs and heart should always be carefully examined before applying it. The first treatment should not be prolonged beyond twentyfive or thirty minutes; later, if the patient's condition makes it seem wise, the treatment may be prolonged to sixty minutes. A treatment begins only when the temperature has reached from 175 to $212 \mathrm{~F}$. A cold cioth on the forehead adds to the patient's comfort. After a treatment the patient is dried, given dry linen and permitted to sleep. 'The evening temperature should be taken on the day of the treatment. Pain which was excruciating before the treatment was begun is often allayed before it is ended. The patient looks forward to the treatment or even asks to have it repeated.

Besides this change in the subjective symptoms, the objective ones also undergo important changes. Polano, ${ }^{5}$ in his first publication concerning this method of treatment, states that chronic pelvic exudates are especially amenable to it. He cites the history of a case in which after twenty sittings a large parametritic exudate entirely disappeared. Everyone who has used hot-air therapy extensively has been able to report similar results. In two of my own patients with hard chronic exudates filling the entire pelvis I found practically a restitutio ad integrum after five to six weeks' treatment. Frequently the hot-air applications do not cause a disappearance of the exudate, but instead cause it to break down, thus making it ripe for incision; after the incision the condition is usually cured. Firm scars in the parametrium and in the vagina, old bands and adhesions which bold the uterus in an abnormal position are made amenable to massage by dry heat. The reason why chronic inflammatory adnexa tumors frequently show objective improvement after the treatment is because they are usually accompanied by a parametritic process or by edema, and these are readily amenable to hot-air therapy.

\section{TREATMENT BY WEIGHTING}

In connection with the hot-air therapy in the abovementioned conditions I wish to mention another form of treatment to which altogether too little attention has been given. I mean the combination of the hot-air therapy with Belastung or Belastungslagerung (treatment by weighting). In looking over the literature I find that this combination is mentioned only by Stoeckel, ${ }^{6}$ Kehrer $^{7}$ and Frankl. ${ }^{8}$ The latter says: "Chronic inflammatory adnexa tumors which are unaccompanied by fever are often greatly improved by a combination of dry heat, massage and Belastung

5. Eine neue Methode der Behandlung chronischer Beckenexu date, Centralbl. f. Gynäk., 1901, No. 30.

6. Diskussionsbemerkungen, Sitzungsb. d. Gesellsch. f. Geburtsh. u. Gynäk. zu Berlin, July 14, 1905.

7. Beitrag zur Behandlung chronischer Beckenexudate, Centralbl. f. Gynäk., 1901, No. 57.

8. Die physikalischen Heilmethoden in der Gynäkologie, 1906, Berlin, Urban and Schwarzenberg. 
(weights). The enlarged adnexa which previous to the hot-air treatment were too sensitive to be amenable to massage and weighting becomes painless, so that a combination of all three forms of treatment can be carried out."

Belastung is nothing new. Diokles, Strato, Celsus, Charcot, Bozeman and Chrobak all employed it, but not until 1897, when W. A. Freund improved the method sufficiently, did it receive more general recognition. $\mathrm{He}$ placed a glass tube speculum in the vagina and filled it with shot. Later Schauta and his pupil Halban modified the method in that they filled a colpeurynter with mercury.

Pincus $^{9}$ still further improved the method by employing Belastungslagerung, that is to say, he brought pressure against the exudate like Schauta, but in addition placed a bag containing clay, shot or sand and weighing from one to two kilo on the patient's abdomen.

The foot of the patient's bed is raised $30 \mathrm{~cm}$., and the weights are kept in place from six to eight hours. By combining the elevation of the foot end of the bed with the application of the external and internal weights, called by Pincus Belastungslagerung, two things are accomplished. The pelvic viscera, especially the uterus and adnexa, are carried up toward the pelvic inlet so that the inflammatory mass in the pelvis is made more accessible to the weights. The inflammatory mass brought between the vaginal and abdominal weight is flattened out like a sponge. This pressure, aided by the Trendelenburg position, brings about an anemia of the inflammatory mass as long as the treatment lasts. Immediately after the weights are removed and the patient assumes the horizontal position a marked reaction sets in, the anemic tissue becomes markedly hyperemic. To the latter the pain-relieving action of the treatment must be attributed.

The indications for the employment of weight therapy are the same as for hot-air therapy. When combining. the hot-air and weight therapy I obtained the best results by alternating the two on successive days. In private I prefer filling the colpeurynter with mercury instead of with shot, as the patient can readily let the mercury run out at a specified time without the aid of the physician.

It is not within the scope of this paper to go into details regarding the various modifications of this method, such as colpeurynter massage, Pincus' mercuryair colpeurynter, etc.; these can be found in Pincus' monograph. I mention them for the sake of completeness, as, in a broad sense, they, too, come under the head of hyperemic treatment.

A judicious combination of the hot-air therapy and the weight therapy is especially advantageous, as the former often affects only the subjective symptoms favorably, while the latter affects the objective ones. Both methods should be employed, not only by the specialist, but also by the general practitioner, as they require only patience and no complicated apparatus. 'That the hotair treatment can also be carried out in dispensary practice is amply proved by Buerger's ${ }^{10}$ and Eltze's ${ }^{11}$ publications.

9. Pincus, Ludwig: Belastungslagerung. Grundzüge einer nichtoperativen Behandlung chronisch entzündlicher Frauenkrankheiten und ihrer Folgezustände, 1905, Wiesbaden.

10. Buerger, O.: Zur Heissluftbehandlung gyn. Erkrankungen. Wiener klinische Wochenschrift, No. 28, 1903.

11. Eltze, H. : Poliklinische Erfahrungen über Heissluftbehandlung. Alte und neue Gynäkologie, Festschrift f. von Winckel, Munchen, 1907.

\section{SUCTION HYPEREMIA FOR UTERTNE INFLAMMATORY} CONDITIONS

Of late the suction cup has also been introduced into gynecologic therapeutics. In $1905 \mathrm{Rudolph}^{\mathbf{1 2}}$ of Heilbronn published the first article regarding it, and was soon followed by Bauer, ${ }^{13}$ Eversmann, ${ }^{14}$ Kroemer, ${ }^{15}$ Lewith ${ }^{16}$ and others. 'They recommended it in inflammatory conditions of the uterus and cervix-that is, in erosions, endometritis and metritis, also for parametritis, amenorrhea and dysmenorrhea. Kroemer even employed it to prevent an infectious process from spreading beyond the uterus after the latter was infected.

The suction glasses have the shape of the well-known old-fashioned glass tube speculum. One extremity is slightly funnel-shaped and receives the cervix. The other end is closed and near it a small tube is attached which connects with the suction pump. The suction cup is made of plain glass so that the degree of hyperemia and the amount of uterine secretion brought out by the suction can be easily watched. The general rules which apply for the use of the suction cup elsewhere apply here: after five minutes' suction, from two to three minutes' rest, etc., in all about one-half hour a day.

I have had considerable experience with the suction treatment in gynecology and believe that the benefits to be derived from it are no better than those attained with other forms of treatment. It appears to me to be expecting too much to cure a metritis or endometritis by treating only the cervix. The whole organ should be treated, and as this can not be done with the suction glasses, other modes of treatment will accomplish as much or more in these conditions. If it seems desirable to scarify an inflamed cervix the use of the cup is of value in increasing the bleeding. Recently favorable results have been reported with the suction glasses, obtained by somewhat modifying the technic. A high degree of suction is employed so that the cervix is aspirated for some distance into the vaginal cup; each suction is kept up a shorter time than usual and the intervals between the suctions are also made shorter, the duration of each sitting being the same as before--onehalf hour. In this way a kind of massage (suction massage) is combined with the hyperemia. Those who use it recommend it in chronic parametritis and in cases of old scars and periuterine adhesions, with the idea of stretching and softening the latter. As far as my own experiences go. I believe that bimanual massage, possibly combined with weight therapy, is more effectual than suction massage.

Attempts have also been made to relieve dysmenorrhea by applying large suction cups to the breasts instead of to the cervix. Theoretically and clinically a close relation exists between the uterus and the breasts. An increase in the physiologic function of the former influences the latter, as the well-known facts during pregnancy and the puerperium go to show. From these premises Polano ${ }^{17}$ concluded that disturbances of menstruation could be influenced by artificial stimulation of the breasts - that is, by the suction treatment. He re-

12. Rudolph. I.: Die Bier'sche Stauung in der Gynäkologischen Praxis. Centralbl. f. Gynäk., 1905. No. 39.

13. Die Bier'sche Stauung in der gynäkologischen Praxis, Wien. klin. Wchnschl., 1905, No. 47.

14. Eversmann, I.: Die Bier'sche Stauung in der Gynäkologie. Centralbl. f. Gynäk., 1905, No. 48.

15. Das Bier'sche Stauungsverfahren in der Gynäkologie, Cen. tralbl. f. Gynäk., 1906. No. 4 .

16. Ueber Stauungsbehandlung bei gynäkologischen Affektionen, Monatschr. f. Geburtsh. u. Gynäk., 1906, xxiv, 551 .

17. Zur Behandlung der Dysmenorrhoe, Centralbl. f. Gynik., 1908 , No. 9 . 
ports some favorable results and states that pain is always diminished. The clinical observations with this form of treatment in dysmenorrhea are only of recent date, so that it is impossible at present to estimate the benefit to be expected from it.

\section{SUCTION HYPEREMIA TO INCREASE FLOW OF MILK}

With reference to the field of obstetrics, suction cups are applied to the breast with the idea of increasing the production of milk in nursing mothers, or to start anew the flow of milk in a breast which had stopped secreting (lactagoge Stauungshyperämie). Jaschke ${ }^{18}$ asserts that it is especially successful in women in whom there was no secretion of milk at all during previous puerperal states. He cites the history of a para who had no milk during her two previous puerperiums. After her third labor her breasts were cupped and as a result she had plenty of milk for her baby. In another patient labor was prematurely induced on account of a flat rachitic pelvis, during the thirty-fifth week of pregnancy. The mother at the time had no colostrum in the breasts; after three days of cupping there was sufficient milk for the child. Another case was one of an old primipara with no colostruni at full term. Her breasts were cupped on the second day postpartum; on the third day the infant was able to obtain forty grams of milk at a single nursing. Jaschke's experience leads him to conclude that "the secretion of milk is so increased by cupping that a causal relationship between artificial hyperemia and increased secretion can not be denied" and that "breast cupping is applicable in cases in which there is no flow of milk, as well as in those in which the breasts do not secrete early enough or in insufficient quantity." $\mathrm{He}$ also recommends cupping as a cure for retracted nipples, which in private practice often are the cause of the mother not nursing her baby.

Polano $^{5,17}$ reports similar good results, one of his cases being especially interesting: In a patient in whom the milk became insufficient seven times during six months, two treatments per day for two days re-established the normal flow each time.

Such evidence demands consideration, and cupping can not be too strongly recommended for these conditions, especially as no harm can be done. The hyperemic treatment in these conditions bids fair to increase the number of nursing women and to do away with artificial feeding to some extent. The explanation of the increased secretion brought about by cupping is to be found in the fact that by moderate suction more arterial blood is brought to each secreting cell, while more forcible suction brings about a venous hyperemia. After the latter has been produced and the suction is stopped a marked arterial hyperemia again sets in. In this way more blood is brought to the gland in a given time than under normal conditions and the breast is better nourished than before. The treatment of puerperal mastitis by suction hyperemia is described in detail in Meyer and Schmieden's book. In my experience the treatment should be begun as soon as the first signs of a mastitis set in. When the treatment is started promptly, pain and inflammatory signs are allayed at once. When pus has once formed the time has come for incision: "ubi pus ibi evacua." The incisions required in conjunction with hyperemic treatment, however, need only be very small. This method has the great advantage of preserving a functionating breast without any disfigurement,

18. Staungshyperïmie als ein die Mllchsecretion förderndes Mittel, Medizinische Klinik, Feb. 23, 1908. while the old method of making large radial incisions left disfiguring scars and often destroyed so much parenchyma that the breast was useless for nursing purposes during her future puerperal states.

I stated above that treatment should be begun when the first symptoms of a mastitis set in. This statement is contrary to the findings of Zangemeister, ${ }^{18}$ who believes that treatment should not be started too early, as it favors suppuration. I am not convinced that this is so; larger statistics only will determine which method gives the better result.

Another indication for the suction treatment in obstetrics is found in the induction of abortion, when the cups are applied to the cervix. This is hardly to br: recommended, as the other methods of inducing abortion are more certain and quicker.

In connection with artificial hyperemia, it is all important to treat the patient's general condition. It is the aim of the hyperemic treatment to increase the flow of blood through the diseased tissue in order that the latter may better resist the deleterious invasion of bacteria. This will be the more easily accomplished if the blood is in good condition, and, therefore, hygienic, dietetic and tonic treatment should not be lost sight of. From what has been said it can not be denied that the hot-air treatment, alone or combined with Belastungslagerung is of great value in the treatment of chronic inflammatory conditions in the female pelvis and that the cupping of breasts is a valuable aid in treating puerperal mastitis and breasts which secrete poorly or not at all. It is, therefore, not going too far when I venture to say that the general practitioner should familiarize himself with these forms of treatment, and that hospitals should do justice to the progress of medical science in establishing so-called "conservative wards" in which the above discussed treatment can be given a thorough trial. If this be impossible, special rooms should be established in gynecologic dispensaries for this purpose. Thus many women would be cured who now are but slightly improved or mutilated by operative treatment.

As a further incentive to the use of conservative methods, let me remind you of the famous Czerny's words: "All operations are accompanied by some danger and are justified only when all other methods of treatment have been exhausted."

1 West Eighty-fifth Street.

\section{PURULENT PLEURITIS: PATHOLOGY AND TREATMENT \\ F. T. BILLINGS, M.D. PITTSBURG}

The pleural sac is kept in its normal condition of simple moisture by a definite lymph circulation; the sto. mata both on the visceral and parietal layers, in health, keep this fluid down to certain limits. The thorax being a closed sac and the pressure within being negative, it follows that the aspirating qualities are usually most efficient. Samuel West" speaks of this as "the lymphatic pump," and shows that with any collection of fluid within the pleura there must be some mechanieal obstruction to the operation of this pump. It is probable there is always more or less absorption of fluid through

19. Die Rehandlung der puerperalen Mastitis mit Saugapparaten, Deutsche med. Wochenschrift, 1908, No. 6.

1. Lancet, London, March 25, 1905. 